\title{
Photonic powering of sensors with bidirectional communication along a single fiber
}

\author{
Jovan Shikoski, ${ }^{* 1}$ Rumen Arnaudov, ${ }^{1}$ and Tinko Eftimov ${ }^{2}$ \\ ${ }^{1}$ Technical University of Sofia, $8 \mathrm{Kl}$. Ohridski Blvd, Sofia 1700, Bulgaria \\ ${ }^{2}$ Université du Québec en Outaouais, Gatineau, QC J8X3X7, Canada
}

Received July 10, 2019; accepted March 23, 2020; published March 31, 2020

\begin{abstract}
In this paper we propose and study simultaneous transmission of photonic power and bidirectional communication to and from sensors via $840 / 1310 \mathrm{~nm}$ WDMs. The photovoltaic converter is used both for power conversion and data transfer from the high-power laser at $808 \mathrm{~nm}$ up to $1 \mathrm{Mb} / \mathrm{s}$ while the $1310 \mathrm{~nm}$ link can be up to $155 \mathrm{Mb} / \mathrm{s}$.
\end{abstract}

Except for the transmission of optical signals, optical fibers can also be used for the transfer of photonic power for remote powering of sensors and electronic devices (power-over-fiber). Systems based on power-over-fiber find applications in hazardous areas [1] because of the characteristics of optical fibers: high galvanic isolation, immunity to electromagnetic noises, absence of sparks, lightning proof, immune to extreme temperature conditions and humidity [2].

Two architectures for the transfer of photonic power are used: wavelength division multiplexing (WDM) and spatial division multiplexing (SDM) or a combination of both $[3 \div 5]$. The data transfer is from the sensor to the base module, while the transfer of optical power is to the sensor [6 $6 \div$ ]. Multiplexing of photonic power transfer at $800 \mathrm{~nm}$ and data transfer at $1310 \mathrm{~nm}$ has been demonstrated $[8 \div 9]$, in which the high-power laser is in CW mode.

In a previous paper we have shown that with a modulated high-power laser diode HPLD (808 nm, $400 \mathrm{~mW}$ ) and a photovoltaic convertor PPC-4E, data at a rate of up to $1 \mathrm{Mb} / \mathrm{s}$ over a multimode fiber [11] can be transmitted.

In the present paper we describe an optically powered bidirectional communication/sensor system using the same laser and PV convertor in a WDM architecture to simultaneously transmit photonic power and command information at $808 \mathrm{~nm}$ to the sensors at a maximum of 1 $\mathrm{Mb} / \mathrm{s}$ as well as to transmit sensor data back to the base module at $1310 \mathrm{~nm}$ at a maximum of $155 \mathrm{MB} / \mathrm{s}$ data transfer.

Specifically, we propose a scheme to power a sensor module with optical power used to charge a Li battery.

\footnotetext{
${ }^{1}$ E-mail: jovanshiko@abv.bg; ${ }^{2}$ E-mail: ra@tu-sofia.bg

${ }^{3}$ E-mail: tinko.eftimov@uqo.ca
}

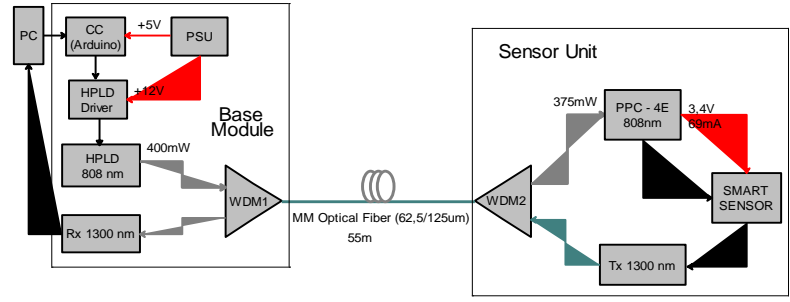

Fig. 1. General architecture to transmit photonic energy to power sensors with bidirectional communication along a single fiber.

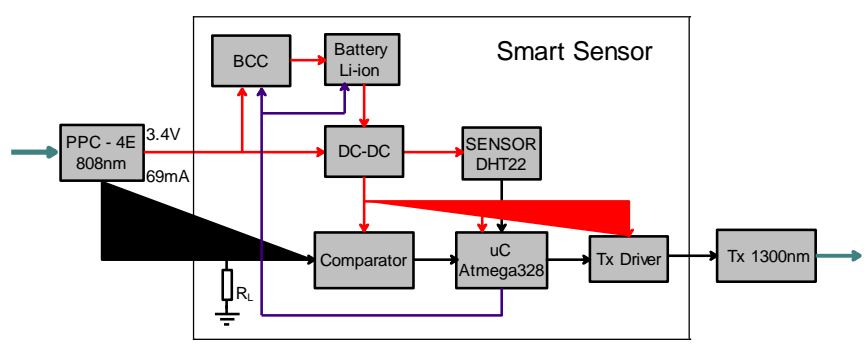

Fig. 2. General architecture to smart sensors.

The suggested general architectures for optical powering of sensors with bidirectional communication along a single fiber is shown in Fig. 1 and Fig. 2. To transmit the photonic power we use the WDM multiplexing architecture. An 840/1310nm WDM1 is used to multiplex into a $62.5 / 125 \mu \mathrm{m}$ multimode fiber and a WDM2 is used to de-multiplex to the sensor module. This configuration allows the transmission of both energy and data along a single fiber by making use of transmitters and receivers operating at different wavelengths. The data on temperature and humidity (DHT22) taken by the sensors are processed by the microcontroller $(\mu \mathrm{C})$ and are transferred by the driver to the optical transmitter Tx, where it is converted into optical signals at $1300 \mathrm{~nm}$. A $155 \mathrm{Mb} / \mathrm{s}$ optical transmitter of the type HFBR-1312TZ is used. The signals are multiplexed by WDM2 and transmitted along a $60 \mathrm{~m}$ long optical fiber to the base module, where they are demultiplexed by WDM1 and are next at the photoreceiver $\mathrm{Rx}(1300 \mathrm{~nm})$, which in this case

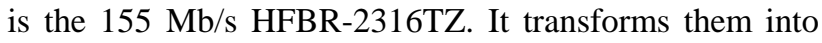
electrical signals and transmits them to the central controller (CC-Arduino) where they are processed. The 
data received from the sensor measurements are transmitted to the computer (PC).

The remote powering of the sensor is realized by charging a power battery (Li-ion). The microcontroller ( $\mu$ C-Atmega328) manages the smart sensor. Apart from the transmission and processing of the measured data by the sensor DHT22, the microcontroller monitors the level of the Li-ion battery charge. When the battery voltage falls below $3 \mathrm{~V}$, the microcontroller sends, to the base module via the transmitter (Tx), a message to charge.

The central controller switches on the high-power laser HPLD $(808 \mathrm{~nm})$ and starts the transmission of photonic power $(400 \mathrm{~mW})$ along an optical fiber to the PV converter PPC-4E which charges the battery via a charge controller device (BCC). While charging, the DC-DC convertor provides the module with electric power from the photovoltaic. The process of charging is continuously monitored by the microcontroller. When the voltage of the battery reaches $4.2 \mathrm{~V}$, the microcontroller sends a message to the basic module to stop the process of optical charging. Figure 3 describes the algorithm for management of the smart sensor.

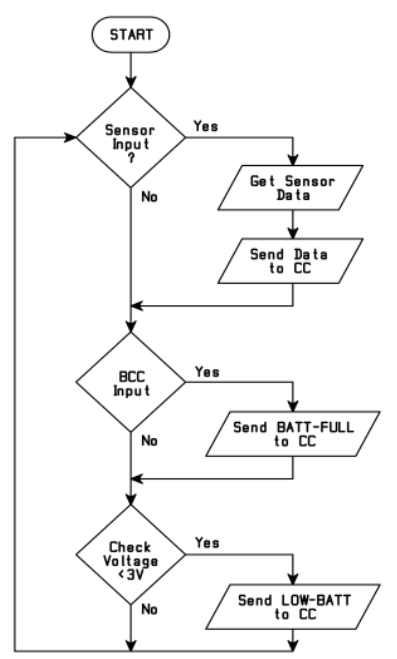

Fig. 3. Algorithm for smart sensor management

Apart from optical energy, the high power laser diode is modulated and transmits information to the sensor. The information signal modulates the continuous optical power generated by the high power laser. In general, this signal sends commands that must be executed by the sensor, such as change of activity, constants, sensor parameters etc. Signals are received by the photovoltaic converter PPC-4E because it can function as a photoreceiver at a bitrate of $1 \mathrm{Mbit} / \mathrm{s}$ [11]. A load resistance of $\mathrm{R}_{\mathrm{L}}=50 \Omega$ is branched at the output of the photovoltaic convertor. The voltage across the resistance is the output signal from the PPC-4E. The initial shape of the signal is restored using a comparator and is transferred to the microcontroller. In this way is realised simultaneous transmission of the photonic energy and the command signals.

The power that the system based on power-over-fiber technology can transfer is determined by its components: laser, optical fibers, WDM multiplexers, optical switches and photovoltaic cells.

To evaluate the transferred electric power ( $\left.\mathrm{P}_{\mathrm{Load}}\right)$ the following quantities are used: the maximum transmitted optical power that does not caus fiber damage $\left(\mathrm{P}_{\text {MaxFiber }}\right)$; optical power of the laser $\left(\mathrm{P}_{\mathrm{HPLD}}\right)$; optical power at the PV input $\left(\mathrm{P}_{\mathrm{IN}}\right)$; total loss along fiber $\left(\alpha_{\mathrm{Fiber}}, \mathrm{dB} / \mathrm{km}\right)$; total losses of all optical connectors $\left(\alpha_{\text {Conn }}\right)$; fiber length $(\mathrm{L})$; efficiency of the PV $\left(\eta_{\mathrm{pv}}\right)$ [12]. Since the considered architecture assures energy transfer at different wavelengths, the losses at the WDM multiplexors must be taken into account $\left(\alpha_{\mathrm{WDM}}, \mathrm{dB}\right)$, as well as the losses at fiber splices $\left(\alpha_{\text {Splice }}, \mathrm{dB}\right)$ :

$$
P_{\mathrm{Load}}=P_{\mathrm{IN}} \eta_{\mathrm{pv}}
$$

The total loss along the optical line is the sum of all losses in the components in the system:

$\alpha=\alpha_{\text {Fiber }}+n_{\text {Conn }} \alpha_{\text {Conn }}+n_{\text {Splice }} \alpha_{\text {Splice }}+n_{\text {WDM }} \alpha_{\mathrm{WDM}}+\alpha_{\text {res }}$,

where $n$ is the number of the corresponding optical components in the optical and $\alpha_{\text {res }}$ are the additional unaccounted losses in the channel. Typically, the value of $\alpha_{\text {res }}$ is about $3 \mathrm{~dB}$.

$$
\mathrm{P}_{\mathrm{IN}}=\mathrm{P}_{\mathrm{HPLD}}-\alpha
$$

for the optical system to function the condition to be fulfilled is:

$$
P_{\text {HPLD }} \leq P_{\text {MaxFiber }}
$$

The maximum power for most multiplexers must be less than $500 \mathrm{~mW}$. To fulfill condition (4) the laser is chosen to be $P_{\text {HPLD }}=400 \mathrm{~mW}$.

The efficiency of the optical system $(\eta)$ is defined as the ratio of the electrical power $\mathrm{P}_{\text {Load }}$ to the optical power $\mathrm{P}_{\mathrm{HPLD}}$ of the high power laser diode (HPLD):

$$
\eta=P_{\text {Load }} / P_{\text {HPLD }}
$$

The maximum distance of the optical power-over-fiber link can be calculated using Eqns. $(1 \div 5)$ and the parameters listed in Table 1 . From the calculations made and for a fiber length of $1 \mathrm{~km}$, the optical power at the photovoltaic input is $P_{\mathrm{IN}} \approx 380 \mathrm{~mW}$. It is known that the photovoltaics that operate at wavelengths from 790 to $850 \mathrm{~nm}$ are GaAs based. Their efficiency is $\eta_{\mathrm{PV}}=52 \%$. The substitution of these parameters in (1) the electric power generated by the PPC-4E will be $P_{\text {Load }}=199 \mathrm{~mW}$. 
Table 1. Partameters used to calculate the maximum distance of the power-over-fiber link.

\begin{tabular}{|c|c|c|c|c|c|c|}
\hline $\begin{array}{c}P_{\mathrm{LD}},(\mathrm{mW}) \\
{[\mathrm{dBm}]}\end{array}$ & $\begin{array}{c}\lambda \\
(\mathrm{nm})\end{array}$ & $\begin{array}{c}\text { Fiber } \\
(\mu \mathrm{m})\end{array}$ & $\begin{array}{c}\alpha_{\text {Fiber }} \\
(\mathrm{dB} / \mathrm{km})\end{array}$ & $\begin{array}{c}\alpha_{\text {Conn }} \\
(\mathrm{dB})\end{array}$ & $\begin{array}{c}\alpha_{\text {Splic }} \\
\mathrm{e} \\
(\mathrm{dB})\end{array}$ & $\begin{array}{c}\alpha_{\text {WDM }} \\
(\mathrm{dB})\end{array}$ \\
\hline $\begin{array}{c}400 \\
{[26.02]}\end{array}$ & 808 & $\begin{array}{c}\mathrm{MM} \\
62.5\end{array}$ & 3 & 0.75 & 0.1 & 0.7 \\
\hline $\begin{array}{c}0.056 \\
{[-12.5]}\end{array}$ & 1300 & $\begin{array}{c}\mathrm{MM} \\
62.5\end{array}$ & 0.7 & 0.75 & 0.1 & 0.6 \\
\hline
\end{tabular}

The method of photonic energy transfer along a fiber for the proposed architecture is experimentally tested for a link length of $60 \mathrm{~m}$. For a laser generated optical power of $P_{\text {HPLD }}=400 \mathrm{~mW}$, the optical power measured at the PPC$4 \mathrm{E}$ is $P_{\mathrm{IN}}=375 \mathrm{~mW}$. After conversion to electrical power, the photovoltaic convertor generates a current of $I_{\text {Load }}=69.8 \mathrm{~mA}$ for a $U_{\text {Load }}=3.43 \mathrm{~V}$, which yields an electrical power $P_{\text {Load }}=239 \mathrm{~mW}$.

Calculations for an emitted power of $P_{\mathrm{HPLD}}=400 \mathrm{~mW}$ and a fiber length $L=60 \mathrm{~m}$ yield an optical power at the PPC-4E input of $385 \mathrm{~mW}$. The difference between the measured and calculated is $10 \mathrm{~mW}$, which shows that the error is less than 3\%. The efficiency of energy transformation of the optical system is calculated using Eq. (5) as $\eta \approx 60 \%$.

The main criterium for the quality of transmitted data is the BER (Bit Error Rate) [10]. The BER measurement is realized by transmitting 33554432 bits at different rates as described in [11].

Table 2. Results obtained for the measured BER in both channels.

\begin{tabular}{|c|c|c|c|c|}
\hline \multirow{2}{*}{$\begin{array}{c}\text { Bit Rate } \\
\text { bit/s }\end{array}$} & \multicolumn{4}{|c|}{ Bit Error Rate - (BER) } \\
\cline { 2 - 5 } & PPC-4E & $\begin{array}{c}\text { PPC-4E } \\
\text { ON } \\
\text { Tx } 1300 \\
\text { nm }\end{array}$ & $\begin{array}{c}\text { Rx1300 } \\
1300 \mathrm{~nm}\end{array}$ & $\begin{array}{c}\text { Rx1300 } \\
\text { ON } \\
\text { HPLD 808 } \\
\text { nm }\end{array}$ \\
\hline 460800 & - & $\begin{array}{c}2 \\
\left(5.96 \times 10^{-8}\right)\end{array}$ & - & - \\
\hline 576000 & 2 & $\begin{array}{c}3 \\
\left(8.94 \times 10^{-8}\right)\end{array}$ & $\left(2.98 \times 10^{-8}\right)$ & $\left(2.98 \times 10^{-8}\right)$ \\
\hline 960000 & $\begin{array}{c}\left(5.96 \times 10^{-8}\right) \\
\left(8.94 \times 10^{-8}\right)\end{array}$ & $\begin{array}{c}5 \\
\left(14.9 \times 10^{-8}\right)\end{array}$ & $\left(8.94 \times 10^{-8}\right)$ & $\begin{array}{c}3 \\
\left(8.94 \times 10^{-8}\right)\end{array}$ \\
\hline
\end{tabular}

Table 2 shows the results of the BER measurements of both channels in both one way and two-way communication. When both lasers are on, the error increases slightly, but still acceptable for reliable communication.

In this paper we propose and experimentally study a method to transmit photonic energy to power sensors, using WDM multiplexing to transmit information in twoway communication along a single fiber over a distance of up to $2 \mathrm{~km}$. The two-way link provides the base module with the possibility to transmit commands as well as to electrically power them in real time. In this way, we can configure and monitor the sensor remotely. This is especially important in hazardous media. The PPC-4E photovoltaic is used simultaneously as a power converter and photoreceiver. The BER measurements made suggest that the system can be used to transmit simultaneously photonic power and data at a rate of up to $1 \mathrm{Mb} / \mathrm{s}$ along a single optical fiber.

\section{References:}

[1] J.C.V. da Silva, E.L.A.S. de Souza, V. Garcia, J.B. Rosolem, C. Floridia, M.A.B. Sanches, Proc. 63rd IWCS Conference, Internat. Wire Cable Symp., Shrewsbury, USA (2014), 832-839.

[2] J.B. Rosolem, E.K. Tomiyama, D.C. Dini, F.R. Bassan, R.S. Penze, A.A. Leonardi, C. Floridia, J.P. Fracarolli, R.M. Teixeira, Proc. SBMO/IEEE MTT-S Internat. Microwave Optoelectr. Conf. (IMOC), Porto de Galinhas, Brazil (2015), 1-5.

[3] T.C. Banwell, R.C. Estes, L.A. Reith, P.W. Shumate, E.M. Vogel, IEEE J. Lightwave Techn. 11(3), 481 (1993).

[4] M. Dumke, G. Heiserich, S. Franke, L. Schulz, L. Overmeyer, Systemics, Cybernetics Informatics 8(1), 55 (2010).

[5] C. Gao, J. Wang, L. Yin, J. Yang, J. Jiang, H. Wan, Proc. SPIE 9270, 927016 (2014).

[6] J. Yan, J. Wang, Y. Lu, J. Jiang, H. Wan, 14th Int. Conf. on Optical Comm. and Networks (ICOCN), Nanjing, China (2015), 15382393.

[7] G. Böttger, M. Dreschmann, C. Klamouris, M. Hübner, M. Röger, A.W. Bett, T. Kueng, J. Becker, W. de Freu, J. Leuthold, IEEE Photon. Technol. Lett. 20(1), 39 (2008).

[8] M. Matsuura, J. Sato, IEEE Photonics J. 7(1), 7900609 (2015).

[9] J. Wang, Q. Li, J. Yan, Y. Ding, Y. Lu, Y. Zhang, H. Wan, 15th Internat. Conf. Opt. Comm. Networks (ICOCN), Hangzhou, China (2016).

[10] S. Kartalopoulos, Optical Bit Error Rate: An Estimation Methodology (2004) Willey- IEEE Press.

[11] J. Shikoski, R. Arnaudov, T. Eftimov, Phot. Lett. Poland 10(3), 70 (2018).

[12] J.B. Rosolem, "Optical Fiber and Wireless Communications", in Power-Over-Fiber Applications for Telecommunications and for Electric Utilities (Intech Open Ltd, London 2017). 